\title{
Comparative assessment of the quality of commercial black and green tea using microbiology analyses
}

\author{
Federica Carraturo ${ }^{1}$, Olga De Castro ${ }^{2 *}$ D, Jacopo Troisi ${ }^{3}$, Adriana De Luca ${ }^{4}$, Armando Masucci ${ }^{5}$, Paola Cennamo ${ }^{6}$, \\ Marco Trifuoggi ${ }^{7}$, Francesco Aliberti ${ }^{1}$ and Marco Guida ${ }^{1}$
}

\begin{abstract}
Background: Drinking tea constitutes a tradition which is deeply rooted in the culture of several countries. Moreover, in recent years, tea consumption is growing all over the world. Improper herbal tea storage (long periods, humid environments) represents a relevant health hazard for consumers because of the growth of bacteria and molds.

Results: This study analyzed 32 samples of commercially available black and green teas - purchased from southern Italy markets and online-shops - and the monitoring of microbiological quality of the tea bag content was performed. Evaluations were conducted with the aim of characterizing pathogens indicated by the European and American guidelines (total bacterial count, fungi and Escherichia coli) and on the research of Pseudomonas spp. and Clostridium perfringens. The presence of ochratoxin A in tea matrix-leaves and infusions was further assessed, using a validated and accredited HPLC-FLD method. Microbial loads, for over $80 \%$ samples, ranged from $1.0 \times 10^{2}$ to $2.8 \times 10^{5} \mathrm{CFU} / \mathrm{g}$ tea: most of identified microorganisms were classified as Bacillaceae. The utilization of rapid detection and identification methods (PCR and sequencing), allowed the characterization of strains of Pseudomonas psychrotolerans, Staphylococcus warneri, Pantoea gaviniae and the isolation of one strain of Clostridium perfringens, whose ability to produce toxins can result in harmful outcomes for consumers. Fungi were isolated from $70 \%$ samples: the most prevalent molds were Aspergillus niger strains, followed by Aspergillus tubingensis. Ochratoxin A was detected in 22 of 32 tea solid samples investigated: concentrations resulted over the indicated limits for food products for 50\% samples.
\end{abstract}

Conclusions: Results obtained demonstrated the need to develop targeted regulations for the safety of herbal teas.

Keywords: Bacteria, Tea, Camellia sinensis, DNA barcoding, Fungi, Microbial contaminant, Ochratoxin A

\section{Background}

The most common tea types, basing on processing, are raw (usually identified as green tea) and ripened (or fermented, black) tea [1]. Fresh tea leaves undergo wilting and heat fixing processes, to sensibly reduce the water content and consent the development of the tea typical flavours. These procedures are carried out trying to avoid microorganisms spoilage due to humid environments and variable temperatures [2]. Despite the positive role of associated bacteria and molds in improving tea quality and taste during the oxidation stage [3], the criticalities in the

\footnotetext{
* Correspondence: odecastr@unina.it

${ }^{2}$ Department of Biology, University of Naples Federico II, Via Foria 223 - Orto

Botanico, 80139 Naples, Italy

Full list of author information is available at the end of the article
}

process are higher with respects to other food production procedures: as a result, the risk of contamination due to harmful pathogens is substantial.

There are no regulations or load limits concerning microbial contamination of teas and infusions, considering that microbiological food safety hazards linked to such food products have rarely been reported [4]. It has to be considered that, although tea contains a natural level of microorganisms, because of its low water activity, the risk related to the growth of microorganisms is not significant, until the product is kept dry: the excessive moisture, indeed, is the main leading to the development of microbiological contamination of tea [5].

In the current research, a hygiene monitoring on 32 different black and green tea confections [Camellia sinensis 
(L.) Kuntze] was performed in order to assess whether the evaluated products, in terms of microbial loads, were in accordance with established guidelines [6, 7].

The research is part of a wider project consisting on a multi-faceted pilot study aimed to analyze 32 brands of European and Italian commercially available tea (16 black teas and 16 green teas) to evaluate: the presence of heavy metals and phthalates (Ferretti V, unpublished data); and adulterations (food fraud) through the a rapid and efficient protocol using DNA barcode (DNA Verity Test) [8].

Our analysis mainly aimed to the microbiological and molecular identification of bacteria and molds in commercial tea samples. In addition to the evaluation of total bacterial count and the research of molds, yeasts and Escherichia coli, as suggested by Tea and Herbal Infusions Europe and American Herbal Product Association [6, 7], microbiological analysis was focused on the detection of Pseudomonas spp. and Clostridium perfringens. Sulphite reducing Clostridia contamination is particularly critical, considering the possibility of the microorganism to produce toxins able to survive to high infusions temperatures [911]. Rapid detection methods, through PCR and sequencing protocols, constitute a tailored support to the fast confirmation of food matrices contamination [12]. The molecular characterization of isolated microbial strains consented the definition of the microbial flora in tea and infusions and emphasized the importance of rapid microorganisms identification techniques to prevent foodborne infections.

The study was also focused on the research both on tea dried comminuted leaf matrices present in the teabags (solid sample) and tea infusions (liquid sample) of ochratoxin A (carcinogenic, immunotoxic, nephrotoxic and hepatotoxic mycotoxin), whose migration from tea has been largely reported $[13,14]$. The fast detection of ochratoxin A (OTA) produced by molds (especially Aspergilli), through analytical chemistry targeted methodologies (HPLC-FLD), represents a valid assessment of the OTA intake levels via tea: the disposal of such data in fast times is able to support the identification of criticalities before tea products market distribution, reducing the health risk for consumers.

\section{Methods}

\section{Tea sampling and sample preparation for the laboratory} analyses

Tea sampling was the same of De Castro et al. [8]. Briefly, a total of 32 tea packages $(C$. sinensis) were purchased from market in Naples (southern Italy) and online-shops (Table 1). All products are available to consumers also by online-shops and represented by 17 different Italian and international famous brands ( 7 and 10, respectively). Of these, 16 samples were fermented tea (black tea) and 16 samples were raw tea (green tea). In addition, decaffeinated and soluble samples were also considered. The tea samples were chosen considering both the sales network (supermarkets, drugstores and herbalist's shops), the price (cheap and expensive), the marketing quality (packaging, publicity and brand) and presence of filters into the packages (except for an accessions of soluble green tea). All information (except for the brand) are reported in Table 1. Tea samples were stored at ambient temperature before the microbiological analyses and mycotoxin characterization. Two different templates were used owing to different analyses: (1) dried for microbiological evaluations (one filter/sample) and mycotoxins (ochratoxin A) detection (5 g/sample); and (2) aqueous infusion for mycotoxins analyses. Briefly, using a microwave, $150 \mathrm{~mL}$ of boiled ultrapure water (ROMIL-SpS Super Purity Solvent, ROMIL) was poured into each beaker containing one filter of tea samples and then left to stand (3-8 $\mathrm{min}$ ) according to manufacturer's instructions (Table 1). The standards (only water) and extracts were prepared in scrupulously clean glassware. Both microbiological and mycotoxins analysis were performed in duplicate.

\section{Microbiological characterization Sample preparation}

The content of each infusion bag tea is singularly weighed into a $50 \mathrm{~mL}$ tube and a 1:10 dilution is prepared with $0.9 \%$ sterile $\mathrm{NaCl}$ solution. Tubes are shaken vigorously for $60 \mathrm{~s}$ and vortexed for 10-20 s. The solutions, basing on each microbial research protocol, are plated on solid agar media through spread or pour plating. Sample is plated in two replicates, setting up two ten-fold dilutions per sample. Plates are then incubated at different temperatures and specific times, based on the microorganism or group of microorganisms researched as reported below. A successive DNA barcoding analyses was employed to characterization of microorganisms isolated from selective and non-selective solid enrichment growth media.

\section{Total bacterial count isolation}

Total bacterial count (TBC) analysis, according to International Organization for Standardization (ISO) procedure [15], consists on pouring $1 \mathrm{~mL}$ from the sample in Plate Count Agar (PCA) (Oxoid, Thermo Fisher Scientific Inc., Waltham, MA, USA); PCA plates are incubated at $30 \pm 1{ }^{\circ} \mathrm{C}$ for $72 \mathrm{~h}$. The totality of colonies is counted. Different morphology colonies are sub-cultured in fresh PCA agar and submitted for molecular analysis.

\section{Molds and yeasts isolation}

Molds and yeasts research, according to ISO procedure [16], was performed by pour plating $1 \mathrm{~mL}$ sample in Rose-Bengal chloramphenicol agar (DRBC, Oxoid, Thermo Fisher Scientific Inc., Waltham, MA, USA); Rose-Bengal agar plates are incubated at $22 \pm$ $1{ }^{\circ} \mathrm{C}$ for $72 \mathrm{~h}$. The totality of colonies is counted. 
Table 1 List of the Italian commercialized black and green tea packages analysed in this study ( $\mathrm{N}$ and $\mathrm{V}$ samples, respectively). For each accession is reported information about the marketing quality (high, medium and low), sales network ( $D=$ discount supermarket; $H=$ herbalist's shop; $S=$ supermarket; $P=$ drugstore) and the price $(\epsilon)[(A),<1 \epsilon$; $(B),<1<\epsilon<2$; $(C), 2<\epsilon<4$; (D), $4<\epsilon<6$; (E), $>6 \epsilon]$. Numbers of filters/package, gr/filter, ingredient and infuse protocol preparation have been copied from the original package

\begin{tabular}{lll}
\hline Code Marketing quality $\neq \begin{array}{l}\text { Sales } \\
\text { network }\end{array}$ & $\begin{array}{c}\text { Price } \\
n^{\circ} \text { filters/ gr/filter Label information } \\
\text { package }\end{array}$ & $\begin{array}{l}\text { Infusions } \\
\text { instructions: } \\
\mathrm{H}_{2} \mathrm{O}^{\circ} \mathrm{C}, \mathrm{min}^{* *}\end{array}$ \\
\hline
\end{tabular}

Black teas

\begin{tabular}{|c|c|c|c|c|c|c|c|}
\hline N1 & Medium & $\mathrm{H}$ & $\mathrm{D}$ & 2 & 1.5 & Organic black teas leaves of Camelia sinensis (L.) Kuntze (100\%) & Bo., 5-8 \\
\hline N2 & Medium-good & $\mathrm{P}, \mathrm{H}$ & $\mathrm{D}$ & 20 & 2 & Tea leaves [Camellia sinensis (L.) Kuntze] & Bo., 5-6 \\
\hline N3 & Good & S & B & 25 & 1.5 & Black tea, aromas & $100,2-3$ \\
\hline N4 & Low-medium & S & C & 15 & 2 & Not reported & Bo., 3 \\
\hline N5 & Good & $\mathrm{P}, \mathrm{H}$ & C & 20 & 1.75 & Black certified tea $100 \%$ & $80,1-3$ \\
\hline N6 & Good & S & B & 25 & 1.5 & Tea & $100,3-5$ \\
\hline N7 & Good & S & $C$ & 25 & 1.5 & Decaffeinated tea & $100,3-5$ \\
\hline N8 & Good & S & B & 25 & 1.5 & Not reported & Bo., 2-3 \\
\hline N9 & Good & S & $C$ & 25 & 2 & Black tea (94\%), lemon aroma (6\%) & $100,3-4$ \\
\hline N10 & Low & S & B & 25 & $1.75^{*}$ & Black tea (100\%) & Bo., 3-5 \\
\hline N11 & Good & S & $\mathrm{D}$ & 23 & 1.5 & Decaffeinated black tea, caffeine $<0.1 \%$ & 100,3 \\
\hline $\mathrm{N} 12$ & Low & S & B & 25 & 1.7 & Black tea & Bo., 3 \\
\hline N13 & Low & S & B & 25 & $2^{*}$ & Black tea (95\%), natural lemon aroma (5\%) & $90-100,3$ \\
\hline N14 & Low & S & B & 25 & $1.75^{*}$ & Black tea leaves & Bo., 3-5 \\
\hline N15 & Medium & $\mathrm{H}$ & C & 20 & 2 & Decaffeinated organic black tea, caffeine $<0.1 \%$ & $100,3-5$ \\
\hline N16 & Good & S & C & 14 & $5+$ & $\begin{array}{l}\text { Sugar, acidifier (citric acid), decaffeinated tea extract, aromas, lemon } \\
\text { juice powdered (0.5\%). Gluten free }\end{array}$ & N.d. \\
\hline
\end{tabular}

Green teas

\begin{tabular}{|c|c|c|c|c|c|c|}
\hline Good & $\mathrm{P}, \mathrm{H}$ & $\mathrm{E}$ & 20 & 2 & Pure leaves of green tea (Camelia sinensis Kuntze) & Bo., 5-7 \\
\hline Medium & $\mathrm{P}, \mathrm{H}$ & $\mathrm{E}$ & 20 & 2 & Green tea leaves (Camelia sinensis) (99\%), bergamot essential oil (1\%) & Bo., 5 \\
\hline Medium & $\mathrm{H}$ & $\mathrm{D}$ & 20 & 1.5 & Organic green tea leave [Camellia sinensis (L.) Kuntze] (100\%) & Bo., 5-8 \\
\hline Medium & $\mathrm{P}, \mathrm{H}$ & $\mathrm{D}$ & 20 & $1.8^{*}$ & Green tea leave & Bo., 3-5 \\
\hline Medium-good & $\mathrm{P}, \mathrm{H}$ & $\mathrm{D}$ & 20 & 2 & Unfermented organic tea (Camellia sinensis L.) leave & Bo., 5-6 \\
\hline Medium & $\mathrm{H}$ & C & 20 & 1.75 & Green tea certified by Fairtrade & 80,3 \\
\hline Medium & $\mathrm{H}$ & $\mathrm{D}$ & 20 & $2^{*}$ & Not reported & Bo., 3-5 \\
\hline Good & S & C & 25 & $1.3^{*}$ & Green tea $(100 \%)$ & $90,2-3$ \\
\hline Good & S & C & 10 & $1.3^{*}$ & $\begin{array}{l}\text { Green tea, aromas, peel of citruses ( } 2.1 \% \text { : grapefruit, lemon, lime, } \\
\text { orange) }\end{array}$ & $90,2-3$ \\
\hline Good & S & C & 10 & $1.3^{*}$ & Green tea, aromas, spices 2\% (anise, cinnamon, liquorice) & $90,2-3$ \\
\hline Good & S & C & 10 & $1.3^{*}$ & Green tea, aromas, mint (7.9\%) & $90,2-3$ \\
\hline Good & S & C & 25 & 1.6 & Green tea & 75,3 \\
\hline Low & S & $\mathrm{B}$ & 25 & $1.75^{*}$ & Green tea & Bo., 3-5 \\
\hline Low & S & B & 25 & $2^{*}$ & Organic green tea & 80,3 \\
\hline Low & D & A & 20 & 1.75 & Green tea & Bo., 3-5 \\
\hline Medium & $S$ & A & - & $125+\dagger$ & $\begin{array}{l}\text { Sugar, acidifier (citric acid), green tea soluble extract, aromas, } \\
\text { ginseng soluble extract }\end{array}$ & N.d. \\
\hline
\end{tabular}

$\neq$, value determined by a questionnaire conducted on 25 people ( 13 females and 12 males); ${ }^{*}$, value deducted; ${ }^{*}$, between a range of two values, the average has been used; $t$, soluble; $+t$, soluble power for $1.5 \mathrm{~L}$ of infusion; Bo., boiling water, temperature used of $90^{\circ} \mathrm{C} ; \mathrm{N}$.d., no datum

Different morphology colonies are sub-cultured in fresh Rose-Bengal agar and submitted for molecular analysis.
Escherichia Coli isolation

The presence of Escherichia coli was evaluated according to ISO procedure [17]. After sample preparation, $1 \mathrm{~mL}$ 
sample is plated in Tryptone Bile Agar with XGlucuronide (TBX, Oxoid, Thermo Fisher Scientific Inc., Waltham, MA, USA), using the pour plate method. Plates are incubated at $44 \pm 1{ }^{\circ} \mathrm{C}$ for $24 \mathrm{~h}$. TBX is a chromogenic medium, able to evidence the presence of Escherichia coli, through the growth of typical light-blue colonies.

\section{Pseudomonas spp. analysis}

According to ISO procedure [18], an aliquot of $100 \mu \mathrm{L}$ sample is spread plated on Pseudomonas Agar Base (Oxoid, Thermo Fisher Scientific Inc., Waltham, MA, USA), then incubated at $37 \pm 1^{\circ} \mathrm{C}$ for $24 \mathrm{~h}$. The presence of typical colonies on Pseudomonas Agar Base, straw colored with green or brown pigmentation, represents presumptive evidence of Pseudomonas spp., further confirmed with additional tests.

\section{Clostridium Perfringens research}

Sulphite reducing Clostridia and Clostridium perfringens research, according to ISO procedure [19], consists on pouring $1 \mathrm{~mL}$ from the sample in Perfringens Tryptose Sulphite Cycloserine agar (TSC, Oxoid, Thermo Fisher Scientific Inc., Waltham, MA, USA); TSC plates are incubated at $37 \pm 1{ }^{\circ} \mathrm{C}$ for $24-48 \mathrm{~h}$. Characteristic colonies show a black precipitate, caused by the reduction of sulfite to sulfide; colonies are often surrounded by a yellow halo. The totality of black colonies is counted. Suspect colonies are submitted for biochemical serotyping analysis which permit to reveal the identity of the presumptive Clostridium spp. through the use of RapID ANA II System (Remel, Thermo Fisher Scientific Inc., Waltham, MA, USA). To each available strip, bacterial suspensions prepared from Tryptone Soya Agar (Oxoid, Thermo Fisher Scientific Inc., Waltham, MA, USA) and inoculation fluid $(2 \mathrm{~mL}$ vials) were inoculated and then incubated at $37 \pm 1{ }^{\circ} \mathrm{C}$ for $4 \mathrm{~h}$ in anaerobic conditions. Eight wells are bifunctional: color changes are interpreted either before and after the addition of provided reagents. The color changes produced by metabolic reactions were interpreted employing ERIC v1.0.771 software (Remel, Thermo Fisher Scientific Inc., Waltham, MA, USA).

\section{DNA barcoding analysis}

Each sample was analysed by suspending a colony from agar plates into $25 \mu \mathrm{l}$ of sterile distilled water. The amplification of genomic DNA was performed using a prototypedemo version of a dedicated PCR kit created for Molds, Yeasts and Bacteria (Lyses \& PCR-GO KIT - DNA free) (De Castro O., Dept. Biology, Naples, Italy). Starting directly from the bacterial or fungal colony, a rapid extraction is performed employing the kit and DNA purification is following required before proceeding with PCR. The disposal of free-DNA reagents (Hot Start Taq Polymerase and reaction buffer and lysis buffer) results advantageous towards PCR inhibitors that could make difficult the amplification of the templates. The amplification of bacteria was performed using the 63f forward (5'- CAG GCC TAA CAC ATG CAA GTC-3') and the 1387r reverse (5'-GGG CGG WGT GTA CAA GGC-3') oligos (Macrogen Inc., Seoul, Rep. of Korea), able to amplify the 16S bacterial rRNA [20]. For the characterization of yeasts and molds, the nuclear internal transcribed spacers (ITS1-2) and 5.8S rDNA were amplified, using ITS5 forward (5'-GGA AGT AAA AGT CGT AAC AAG G-3') and ITS4 reverse (5'TCC TCC GCT TAT TGA TAT GC-3') primers (Macrogen Inc., Seoul, Rep. of Korea) [21]. Amplified samples were purified using PEG8000 precipitation (PEG 20\%, $\mathrm{NaCl}$ $2.5 \mathrm{M}$ ): sequencing reactions were run - using the Di Maio and De Castro method [22] - loading $10 \mathrm{ng} / 100 \mathrm{bp}$ from each of the purified templates, employing Bright Dye Terminator Cycle Sequencing Kit, based on the use of a fluorescent dye (ICloning, McLab, San Francisco, CA, USA). Reactions were sequenced with a 3130 Genetic Analyzer (Applied Biosystems, Life Technologies, Thermo Fisher Scientific Inc., Waltham, MA, USA), then interpreted with $A B$ DNA Sequencing Analysis version 5.2 software (Applied Biosystems, Thermo Fisher Scientific Inc., Waltham, MA, USA), supported by an additional editing tool, Chromas lite version 2.1.1 (http://technelysium.com.au/?page_id=13). The characterization of the isolated strains was made employing BLASTN ver. 2.2.29 [23], identifying the microorganisms by choosing the highest percentage of identity with a $95 \%$ cut-off and a minimum $E$-value lower than $\mathrm{E}^{-4}$.

\section{Mycotoxin characterization \\ Ochratoxine a determination}

Five grams each sample were extracted with $50 \mathrm{~mL}$ of $\mathrm{CH}_{3} \mathrm{OH} / \mathrm{NaHCO}_{3}$ in water $1 \%$, (70/30) with a 30 min agitation in an orbital shaker at $20^{\circ} \mathrm{C}$. Sample extract was filtered on Whatman n.40 paper (Exacta Optech, San Prospero, MO, Italy). Five $\mathrm{mL}$ of the extract were diluted with $20 \mathrm{~mL}$ of Phosphate Buffer Solution (PBS), which contains $8 \mathrm{~g} \mathrm{NaCl}, 1.2 \mathrm{~g} \mathrm{NaHCO}_{3}, 0.2 \mathrm{~g} \mathrm{KH}_{2} \mathrm{PO}_{4}, 0.2 \mathrm{~g}$ $\mathrm{KCl}$ in $1 \mathrm{~L}$ of water; final $\mathrm{pH}$ was adjusted to 7.0 using $\mathrm{HCl}$. The diluted extract was passed through an immunoaffinity column (Vicam, Milford, MA, USA) to lead ochratoxin A (OTA) contained in the extract to the antibody. The elution velocity was set to $2 \mathrm{drop} / \mathrm{s}$. The column was subsequently washed with $10 \mathrm{~mL}$ PBS twice and then with $10 \mathrm{~mL}$ water. Ochratoxin A was recovered by means $1 \mathrm{~mL}$ of methanol that, passing thought the column, denaturated the antibody and solubilized them.

Ochratoxin A determination was made with an HPLC Prominence (Shimadzu, Kyoto, Japan) provided of two pumps LC20AD XR, a degaser DGU20A3, an autosampler SIL20AD XR, an oven CTO10AS VP and a fluormetric detector FP2020 Plus (Jasco, Tokyo, Japan). Separation step 
Table 2 Values of total microbiological counts in the black and green tea samples. The analyses were performed in duplicate (R1 and R2)

\begin{tabular}{|c|c|c|c|c|c|c|c|c|c|c|c|c|c|c|c|c|c|}
\hline \multirow{3}{*}{$\begin{array}{l}\text { Black tea } \\
\text { sample } \\
\text { N1 }\end{array}$} & \multicolumn{4}{|c|}{ Bacteria } & \multicolumn{4}{|c|}{$\underline{\text { Molds and Yeasts }}$} & \multirow{3}{*}{$\begin{array}{l}\text { Green tea } \\
\text { sample } \\
\text { V1 }\end{array}$} & \multicolumn{4}{|c|}{ Bacteria } & \multicolumn{4}{|c|}{ Molds and Yeasts } \\
\hline & \multirow{2}{*}{$\begin{array}{l}\text { R1 } \\
\text { CFU/g } \\
180\end{array}$} & \multirow{2}{*}{$\begin{array}{l}\text { R2 } \\
\text { CFU/g } \\
200\end{array}$} & \multicolumn{2}{|c|}{$\begin{array}{l}\text { Mean } \pm \text { S.D. } \\
\text { CFU/g }\end{array}$} & \multirow{2}{*}{$\begin{array}{l}\text { R1 } \\
\text { CFU/g } \\
0\end{array}$} & \multirow{2}{*}{$\begin{array}{l}\text { R2 } \\
\text { CFU/g } \\
0\end{array}$} & \multicolumn{2}{|c|}{$\begin{array}{l}\text { Mean } \pm \text { S.D. } \\
\text { CFU/g }\end{array}$} & & \multirow{2}{*}{$\begin{array}{l}\text { R1 } \\
\text { CFU/g } \\
471\end{array}$} & \multirow{2}{*}{$\begin{array}{l}\text { R2 } \\
\text { CFU/g } \\
489\end{array}$} & \multicolumn{2}{|c|}{$\begin{array}{l}\text { Mean } \pm \text { S.D. } \\
\text { CFU/g }\end{array}$} & \multirow{2}{*}{$\begin{array}{l}\text { R1 } \\
\text { CFU/g } \\
272\end{array}$} & \multirow{2}{*}{$\begin{array}{l}\text { R2 } \\
\text { CFU/g } \\
298\end{array}$} & \multicolumn{2}{|c|}{$\begin{array}{l}\text { Mean } \pm \text { S.D. } \\
\text { CFU/g }\end{array}$} \\
\hline & & & 190 & \pm 14.1 & & & 0 & \pm 0 & & & & 480 & \pm 12.7 & & & 285 & \pm 18.4 \\
\hline N2 & 0 & 0 & 0 & \pm 0 & 0 & 0 & 0 & \pm 0 & V2 & 2304 & 2296 & 2300 & \pm 5.7 & 895 & 905 & 900 & \pm 7.1 \\
\hline N3 & 127 & 113 & 120 & \pm 9.9 & 57 & 43 & 50 & \pm 9.9 & V3 & 354 & 346 & 350 & \pm 5.7 & 224 & 236 & 230 & \pm 8.5 \\
\hline N4 & 6730 & 6750 & 6740 & \pm 14.1 & 192 & 208 & 200 & \pm 11.3 & V4 & 53 & 47 & 50 & \pm 4.2 & 8 & 12 & 10 & \pm 2.8 \\
\hline N5 & 380 & 400 & 390 & \pm 14.1 & 247 & 233 & 240 & \pm 9.9 & V5 & 124 & 118 & 121 & \pm 4.2 & 25 & 35 & 30 & \pm 7.1 \\
\hline N6 & 4890 & 4870 & 4880 & \pm 14.1 & 3009 & 3061 & 3035 & \pm 36.8 & V6 & 0 & 0 & 0 & \pm 0 & 0 & 0 & 0 & \pm 0 \\
\hline N7 & 0 & 0 & 0 & \pm 0 & 0 & 0 & 0 & \pm 0 & V7 & 0 & 0 & 0 & \pm 0 & 0 & 0 & 0 & \pm 0 \\
\hline N8 & 248 & 232 & 240 & \pm 11.3 & 216 & 204 & 210 & \pm 8.5 & V8 & 487 & 493 & 490 & \pm 4.2 & 378 & 402 & 390 & \pm 17.0 \\
\hline N9 & 1150 & 1110 & 1130 & \pm 28.3 & 384 & 396 & 390 & \pm 8.5 & V9 & 1212 & 1218 & 1215 & \pm 4.2 & 235 & 245 & 240 & \pm 7.1 \\
\hline N10 & 624 & 696 & 660 & \pm 50.9 & 166 & 154 & 160 & \pm 8.5 & V10 & 534 & 546 & 540 & \pm 8.5 & 223 & 237 & 230 & \pm 9.9 \\
\hline N11 & 198 & 202 & 200 & \pm 2.8 & 0 & 0 & 0 & \pm 0 & V11 & 1437 & 1423 & 1430 & \pm 9.9 & 284 & 296 & 290 & \pm 8.5 \\
\hline $\mathrm{N} 12$ & 410 & 400 & 405 & \pm 7.1 & 180 & 200 & 190 & \pm 14.1 & V12 & 2626 & 2634 & 2630 & \pm 5.7 & 172 & 168 & 170 & \pm 2.8 \\
\hline N13 & 117 & 103 & 110 & \pm 9.9 & 0 & 0 & 0 & \pm 0 & V13 & 17450 & 17498 & 17474 & \pm 33.9 & 4420 & 4490 & 4455 & \pm 49.5 \\
\hline N14 & 685 & 695 & 690 & \pm 7.1 & 434 & 416 & 425 & \pm 12.7 & V14 & 623 & 637 & 630 & \pm 9.9 & 254 & 246 & 250 & \pm 5.7 \\
\hline N15 & 189 & 201 & 195 & \pm 8.5 & 0 & 0 & 0 & \pm 0 & V15 & 13790 & 13810 & 13800 & \pm 14.1 & 2910 & 2890 & 2900 & \pm 14.1 \\
\hline N16 & 0 & 0 & 0 & \pm 0 & 0 & 0 & 0 & \pm 0 & V16 & 0 & 0 & 0 & \pm 0 & 0 & 0 & 0 & \pm 0 \\
\hline
\end{tabular}

Table 3 Microbial taxa isolated from black and green tea samples according to the DNA barcoding characterization

\begin{tabular}{|c|c|c|c|c|c|c|c|}
\hline Bacteria & Black teas & Green teas & Total & Molds & Black teas & Green teas & Total \\
\hline Bacillus amyloliquefaciens & 3 & 4 & 7 & Aspergillus niger & 6 & 10 & 16 \\
\hline Bacillus aryabattai & 0 & 2 & 2 & Aspergillus tubingensis & 1 & 3 & 4 \\
\hline Bacillus cereus & 4 & 5 & 9 & Penicillium commune & 1 & 1 & 2 \\
\hline Bacillus circulans & 1 & 0 & 1 & Penicillium rubens & 0 & 1 & 1 \\
\hline Bacillus drentensis & 0 & 1 & 1 & Penicillium brevicompactum & 0 & 1 & 1 \\
\hline Bacillus endophyticus & 0 & 2 & 2 & Rhizopus oryzae & 1 & 0 & 1 \\
\hline Bacillus licheniformis & 3 & 3 & 6 & Cladosporium ramotenellum & 1 & 0 & 1 \\
\hline Bacillus megaterium & 0 & 2 & 2 & Total (7 species) & 10 & 16 & 26 \\
\hline Bacillus methylotrophicus & 0 & 1 & 1 & & & & \\
\hline Bacillus pseudomycoides & 1 & 0 & 1 & & & & \\
\hline Bacillus pumilus & 2 & 2 & 4 & & & & \\
\hline Bacillus subtilis & 3 & 6 & 9 & & & & \\
\hline Bacillus tequilensis & 0 & 2 & 2 & Yeasts & Black teas & Green teas & Total \\
\hline Bacillus thuringensis & 7 & 1 & 8 & Cryptococcus neoformans & 0 & 1 & 1 \\
\hline Clostridium perfringens & 0 & 1 & 1 & Rhodotorula mucillaginosa & 1 & 0 & 1 \\
\hline Paenibacillus cineris & 1 & 0 & 1 & Sporidiobolis ruineniae & 1 & 0 & 1 \\
\hline Paenibacillus lactis & 0 & 1 & 1 & Total (3 species) & 2 & 1 & 3 \\
\hline Paenibacillus taichungens & 0 & 1 & 1 & & & & \\
\hline Pantoea gaviniae & 1 & 0 & 1 & & & & \\
\hline Pseudomonas psychrotolerans & 1 & 0 & 1 & & & & \\
\hline Staphylococcus warneri & 1 & 0 & 1 & & & & \\
\hline Total (21 species) & 28 & 34 & 62 & & & & \\
\hline
\end{tabular}


was achieved with a Kintex C18 column (Phenomenex, Torrance, CA, USA), $25 \mathrm{~cm}$ length, $4.6 \mathrm{~mm}$ internal diameter. Samples were injected with a $50 \mu \mathrm{L}$ volume. For the identification and quantification of ochratoxin A, the mobile phase consisted of methanol/acetonitrile/acetic acid $(99 / 99 / 2, v / v / v)$ setting a flow rate of $1 \mathrm{~mL} / \mathrm{min}$. For detecting the fluorescence, samples were excited at a $333 \mathrm{~nm}$ wavelength and by emitting a $466 \mathrm{~nm}$ wavelength. The evalutation of the formation of methyl ester with borontrifluoride $\left(\mathrm{BF}_{3}\right)$ resulted functional to confirm the presence of OTA in the samples under analysis: the protocol consisted on drying $1 \mathrm{~mL}$ purified extract (which underwent to ochratoxin detection via HPLC) or $1 \mathrm{~mL}$ standard solution (with a $4 \mathrm{ng} / \mathrm{mL}$ concentration), employing a nitrogen stream; samples were then re-dissolved in $1 \mathrm{~mL} \mathrm{BF}_{3}$. Following an incubation at $60{ }^{\circ} \mathrm{C}$ for $15 \mathrm{~min}$, samples underwent a further HPLC chromatographic analysis. The methylester OTA retention time of was shifted from $10.2 \mathrm{~min}$ to $16.8 \mathrm{~min}$ instead. The ochratoxin A concentrations were quantified using the calibration curve method, using 2',4'-difluoro-4-hydroxy-3-biphenylcarboxylic acid (Diflunisal) as internal standard. The samples were analyzed in a PC generated casual sequence. A "blank" sample and a standard were analyzed every 10 sample. Statistical analysis was performed using Statistica software (StatSoft, Oklahoma, USA) and Minitab (Minitab Inc., Pennsylvania, USA). Standard and samples were analysed in triplicate. The normal distribution of data was verified using the Kolmogorov-Smirov test. The comparison between groups (green compared to black teas) was made by means t-test.

\section{Results}

\section{Microbiological characterization}

By applying the guidelines recommended by Tea and Herbal Infusions Europe and American Herbal Product Association, [6, 7], all the batches of teas analyzed were of satisfactory microbiological quality, excepting V5 sample, due to the presence of Clostridium perfringens (ranging from 1 to $1 \times 10^{2} \mathrm{CFU} / \mathrm{g}$ ).

Values of total bacterial counts, molds and yeasts research for the samples of black $\left(\mathrm{N}_{\mathrm{n}}\right)$ and green $\left(\mathrm{V}_{\mathrm{n}}\right)$ tea are shown in Table 2. Green teas total bacterial count presented higher microbial loads compared to black teas. The analysis of black teas brought out that only samples N4, N6 and N9 showed microbial loads higher than $10^{3}$. Results regarding molds and yeasts never reached the $10^{5}$ indicated load limit. (Table 2).

According to the DNA barcoding characterization, 91 taxa among bacteria (62 of which 21 species), molds (26 of which 7 species) and yeasts (3 species) were identified, as shown in Table 3, Figs. 1, 2 and 3; 40 taxa were from black and 51 from green teas samples. For both tea varieties, around $70 \%$ isolates were bacteria (70\% black vs $67 \%$ green teas) and the $30 \%$

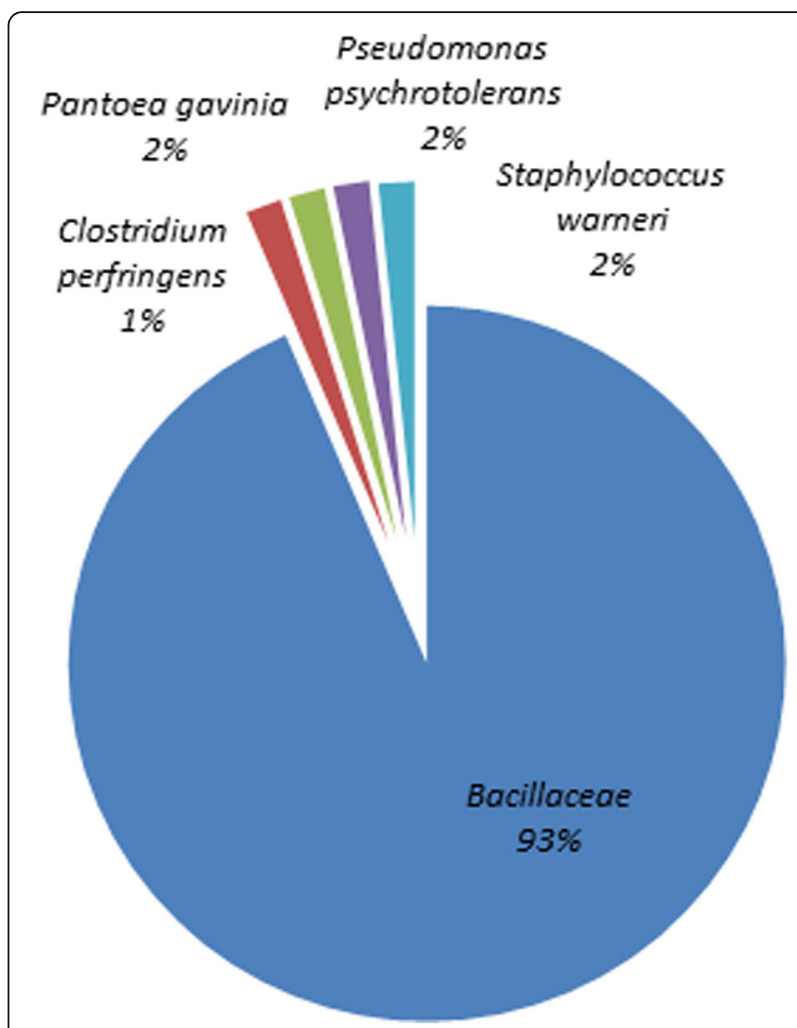

Fig. 1 Frequency of the bacterial species isolated from tea samples according to the DNA barcoding characterization

were molds ( $25 \%$ black vs $31 \%$ green teas) and yeasts ( $5 \%$ black vs $2 \%$ green teas).

The identified bacterial species are listed in Table 3. Most bacteria (68\% total isolates) belong to the Bacillaceae family (93\%, 58 taxa) (Fig. 1 and Table 3), with a prevalence of Bacillus thuringensis (seven isolates) and

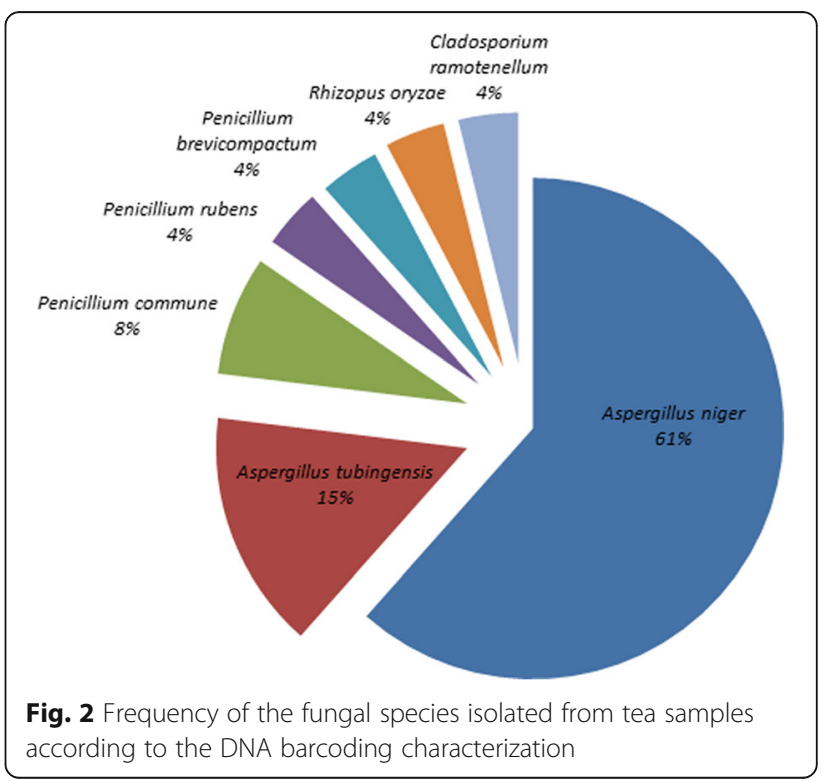




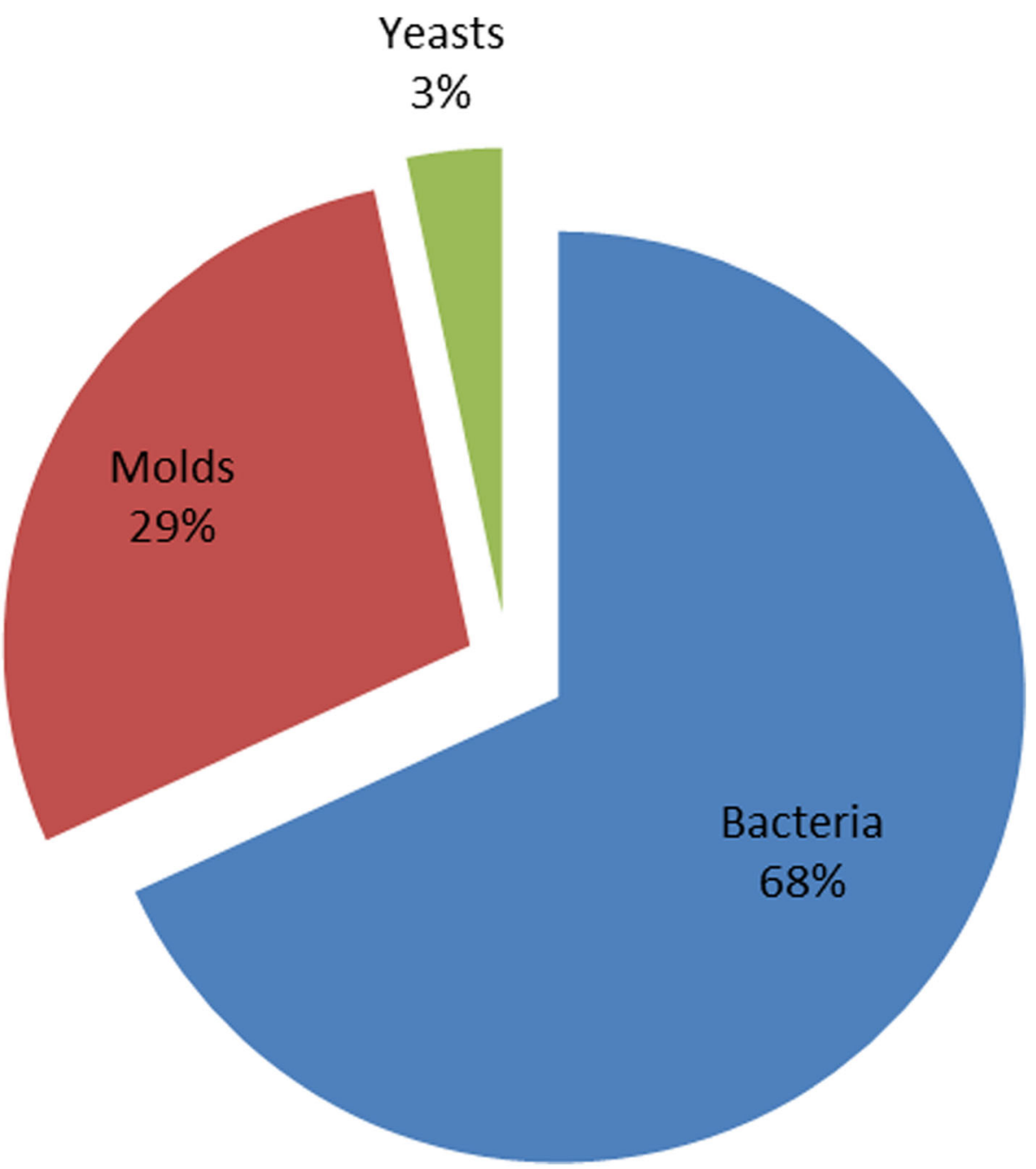

Fig. 3 Relative frequency of Bacteria, Molds, and Yeasts isolated from tea samples

Bacillus cereus (four isolates) in black teas, and a prevalence of Bacillus subtilis (six isolates), Bacillus cereus (five isolates) and Bacillus amyloliquefaciens (four isolates) in green teas. Considering black tea samples, beyond Bacilli and Paenibacilli, three taxa from different families were identified: Pantoea gavinia, Pseudomonas psychrotolerans and Staphylococcus warneri. According to the bacterial families, green teas evidenced a bacterial diversity, with respects to Bacillaceae, only in one case (V5 sample) where the potentially pathogenic spore producing Clostridium perfringens was isolated.

Data regarding molds (Figs. 2 and 3 and Table 3) evidence that the majority of isolates belongs to Aspergillus genus, mostly Aspergillus niger and Aspergillus tubingensis. While, from black teas, taxa of Cladosporium ramotenellum (N8 sample) and Rhizopus oryzae (N10 sample) were identified, mostly Penicillium species (Penicillium commune, V4 sample; Penicillium rubens, V5 sample; and Penicillium brevicompactum, V15 sample) were isolated from green tea samples. Only three yeasts were identified: Cryptococcus neoformans from green tea sample (V15 sample); Rhodotorula mucillaginosa and Sporidiobolis ruineniae isolated from black tea (N6 sample) (Table 3).

\section{Mycotoxin characterization Ochratoxine a: Infusion evaluation}

OTA was detectable in $68.8 \%$ of the green tea infuses and in $37.5 \%$ of the black tea infuses. The mean concentration was higher in the black tea samples, even not significantly $(0.06 \pm 0.03 \mathrm{Vs} 0.04 \pm 0.02[\mu \mathrm{g} / \mathrm{L}]$ of green tea). The OTA transfer ratio during the infusion process ranged between $33.65 \pm 4.37 \%$ for the black tea and $54.47 \pm 14.48 \%$ for the green tea (Table 4 ).

\section{Ochratoxine a: Leaf evaluation}

Ochratoxine A (OTA) was detectable in $82.5 \%$ of green and black tea samples (Fig. 4 and Table 5). OTA mean concentration was lower in black tea compared with 
Table 4 Ochratoxin A concentration in the tea infusions samples

\begin{tabular}{llll}
\hline $\begin{array}{l}\text { Sample } \\
\text { (Black tea) }\end{array}$ & $\begin{array}{l}\text { Ochratoxin A } \\
\text { (ng/L) }\end{array}$ & $\begin{array}{l}\text { Sample } \\
\text { Green tea })\end{array}$ & $\begin{array}{l}\text { Ochratoxin A } \\
\text { (ng/L) }\end{array}$ \\
\hline N01 & $0.1 \pm 0.0$ & V01 & $0.2 \pm 0.0$ \\
N02 & $0.1 \pm 0.0$ & V02 & $0.1 \pm 0.2$ \\
N03 & $0.8 \pm 0.2$ & V03 & $0.6 \pm 0.1$ \\
N04 & $0.4 \pm 0.1$ & V04 & $0.8 \pm 0.2$ \\
N05 & $0.4 \pm 0.1$ & V05 & $0.4 \pm 0.1$ \\
N06 & $0.1 \pm 0.0$ & V06 & $0.4 \pm 0.1$ \\
N07 & $0.1 \pm 0.0$ & V07 & $0.1 \pm 0.2$ \\
N08 & $0.1 \pm 0.0$ & V08 & $0.6 \pm 0.1$ \\
N09 & $0.1 \pm 0.0$ & V09 & $0.6 \pm 0.1$ \\
N10 & $0.1 \pm 0.0$ & V10 & $0.4 \pm 0.1$ \\
N11 & $0.1 \pm 0.0$ & V11 & $0.1 \pm 0.0$ \\
N12 & $0.6 \pm 0.1$ & V12 & $0.4 \pm 0.1$ \\
N13 & $1.0 \pm 0.2$ & V13 & $0.2 \pm 0.0$ \\
N14 & $0.4 \pm 0.1$ & V14 & $0.2 \pm 0.0$ \\
N15 & $0.1 \pm 0.0$ & V15 & $0.1 \pm 0.0$ \\
N16 & $0.1 \pm 0.0$ & V16 & $0.1 \pm 0.0$ \\
\hline
\end{tabular}

green tea, although not statistically significant $(6.26 \pm$ 7.13 vs $7.22 \pm 6.6[\mu \mathrm{g} / \mathrm{Kg}])$. The highest concentration was found in a black tea sample $(21.49 \mu \mathrm{g} / \mathrm{Kg}$, N13 sample) (Fig. 4 and Table 5). All the instant soluble samples had not detectable levels of OTA $(<0.01 \mu \mathrm{g} / \mathrm{Kg})$.

\section{Discussion}

\section{Microbiology}

According to our data, green teas evidenced higher microbial loads $\left(1.7 \times 10^{4} \mathrm{CFU} / \mathrm{g}\right)$ with respect to black teas. Similarly, isolated molds and yeasts, although widely within the $10^{5} \mathrm{CFU} / g$ recommended limit $[6,7]$, highlight a numerousness, which, for some samples, could justify possible alterations of the product.

Biological tea products analyzed (ten samples: N1, N2, N5, N13, N15, V3, V5, V6, V7, V14), compared to our nonbio tea matrices (22 samples), present lower microbial loads, though variable and, in $30 \%$ cases, the product was microbiologically sterile. Teas not reporting the biological certification, presented a lower microbiological sterility rate (14\%). It would be useful to verify the processes to which such products are submitted before commercialization, given that, without a thermal or likewise treatment, it is not easily achievable. The generic 2:1 bacteria:fungi ratio, obtained through molecular biology evaluations, does not result peculiar, considering that the majority of food products of plant origin show such rates [24]. On the other hand, bacterial and fungal species differentiation resulted important: especially for molds, the proper classification allows the identification of aflatoxins producing species, able to resist to teas and infusions extraction process.
According to our molecular analyses, the highest proportion of isolated strains from green tea (51 strains), compared to black tea samples (40 strains), confirmed the higher microbial loads registered for this variety of tea. Moreover, the 70:30 bacteria:molds/yeasts ratio traces the 2:1 bacteria:fungi ratio from the microbiological analysis. The available data concerning identified bacterial strains confirm previous researches reporting Bacillaceae and Paenibacillaceae together with Enterobacteriaceae, as the most frequently identified bacterial species [25]. Bacillaceae are easily isolated from food matrices and generally do not constitute a risk for the health of consumers. Over the Bacilli and Paenibacilli, the bacterial diversity was represented by the isolation of: Pseudomonas psychrotolerans, Staphylococcus warneri, Pantoea gaviniae. The isolation of Pseudomonadaceae and Staphylococcaceae can be considered common, since these bacteria are naturally present in soil [26] and, however, such microorganisms could not survive at high temperatures [27, 28]. On the other hand, interesting resulted the isolation of the facultatively anaerobic strain of Pantoea gaviniae, from sample N9: a recent study demonstrated that Pantoea gaviniae, together with Pantoea calida, are the closest phylogenetic relatives of Pantoea theicola, which is typical from black tea: this strain was isolated from black tea extract heated at $90{ }^{\circ} \mathrm{C}$ [29], indicating the potential of the isolated microorganism to resist not only to anaerobic conditions, but also to high temperatures [30]. Pantoea sp. is an opportunistic pathogen, isolated from different hosts, belonging to the Enterobacteriaceae family, usually employed as indicators for potential contaminations and not proper storage of food products [30]. One Clostridium perfringens strain, whose identification was also confirmed through molecular biology analysis, was isolated from sample V5, biological green tea, with a $50 \mathrm{CFU} / \mathrm{g}$ bacterial load. Clostridium perfringens is an anaerobic obligate bacterium, surviving to low moisture and oxygen levels, well known for its ability of producing toxins, which result crucial for the onset of foodborne pathologies [31]. Since teas are dehydrated, it can be hypothesized that the isolated germs were spores forms, thus not metabolically active for toxins production. In this case, the storage of the product in humidity-free environments is critical as reported by [9-11].

Fungi were isolated from the majority of samples: four fungal genera (Aspergillus, Penicillium, Rhyzopus and Cladosporium) and seven species were detected. The most prevalent microrganisms were Aspergillus niger and $A$. tubingensis, followed by Penicillium (Penicillium commune, Penicillium brevicompactum and Penicillium rubens), Cladosporium and Rhyzopus species. Studies regarding the research of molds in teas and herbal infusions reported that Aspergiullus and Penicillium species generally prevail, followed by microrganisms belonging to Cladosporium, Alternaria, Rhizopus, Absidia and Trichoderma genera [32]. 


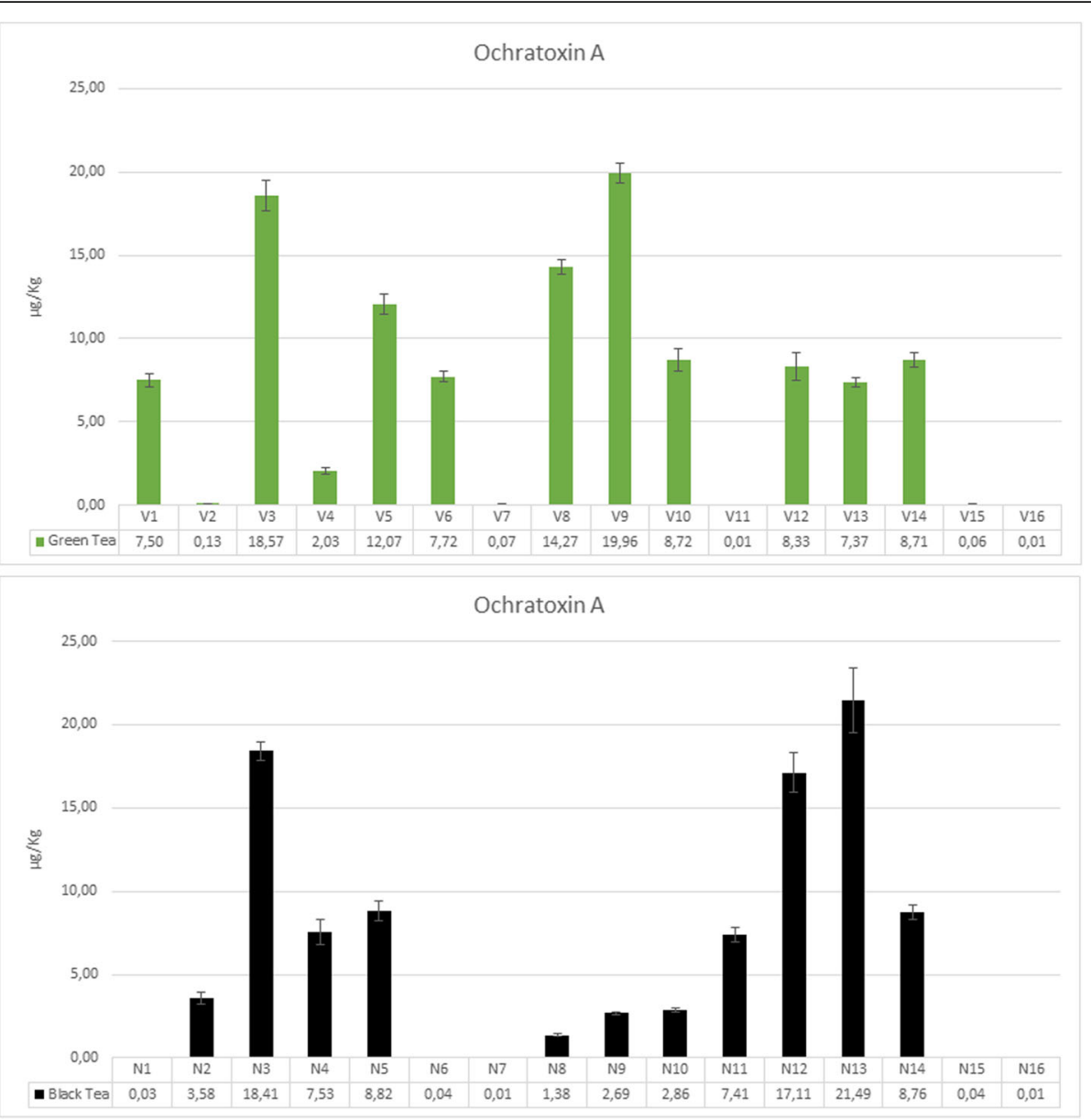

Fig. 4 Ochratoxin A concentrations values $(\mu \mathrm{g} / \mathrm{kg}$ ) in the dried comminuted leaf matrices of the black and green teabags. Further details in Table 5

Aspergillus niger, together with Aspergillus tubingensis, belonging to the black Aspergilli group, represent the most frequently isolated fungal contaminants in our tea samples. The human health risk linked to these fungal species lays in their ability to produce the mycotoxins ochratoxin A (OTA), nephrotoxic and carcinogenic toxins which some microorganisms from Aspergillus and Penicillium genera are able to produce [33]. Beyond Aspergillus genus, Penicillium species (especially Penicillium commune) are commonly isolated from various food samples, included tea [34, 35]. Penicillium brevicompactum is an indoor mould producing a mycotoxin, the mycophenolic acid (MPA). This fungal specie can be isolated from several food matrices [36]. Rhizopus oryzae is a fungal specie which constitutes saprotroph in soil, dung, and spoiled vegetation and it generally used for the fermentation of specific foods [37]; in addition, several species are opportunistic and are able to infect humans [38]. Cladosporium ramotenellum is a widely distributed saprobic mold and has been recently isolated from hypersaline water [39], but also from food matrices (cheese) [40]. In general, Rhizopus and Cladosporium genera, as much as Penicillium, being soil-dwelling microorganisms, are not considered risky for consumers, especially considering the tea as a food matrix.

Yeasts resulted the least isolated microorganisms from the two varieties of tea: two strains were isolated from black tea samples, Rhodotorula mucilaginosa and Sporidiobolus ruineniae (both isolated from sample N6), one from green tea, Cryptococcus neoformans. Rhodotorula mucilaginosa is a basidiomycetous yeast, which can be isolated from air and soil, but also from human skin, stool and food. Even though the majority of Rhodotorula species are non-pathogenic, Rhodotorula mucilaginosa in particular, results the most frequently isolated from human infections [41]. Sporidiobolus ruineniae has been previously isolated from fermented tea [42], but possesses a low resistance to high temperatures (optimum growth range from $15{ }^{\circ} \mathrm{C}$ to $35{ }^{\circ} \mathrm{C}$ ) [42] such as those employed for tea and infusions heating. The analysis of V15 green tea evidenced the presence of Cryptococcus neoformans, an encapsulated yeast, opportunistic fungal 
Table 5 Ochratoxin A concentration in the dried leaves matrices of teabags

\begin{tabular}{llll}
\hline $\begin{array}{l}\text { Sample } \\
\text { (Green tea) }\end{array}$ & $\begin{array}{l}\text { Ochratoxin A } \\
\pm \text { S.D. }(\mu \mathrm{g} / \mathrm{Kg})\end{array}$ & $\begin{array}{l}\text { Sample } \\
\text { (Black tea) }\end{array}$ & $\begin{array}{l}\text { Ochratoxin A } \\
\pm \text { S.D. }(\mu \mathrm{g} / \mathrm{Kg})\end{array}$ \\
\hline V1 & $7.5 \pm 0.37$ & $\mathrm{~N} 1$ & $0.03 \pm 0.00$ \\
V2 & $0.13 \pm 0.01$ & $\mathrm{~N} 2$ & $3.58 \pm 0.36$ \\
V3 & $18.57 \pm 0.93$ & $\mathrm{~N} 3$ & $18.41 \pm 0.55$ \\
V4 & $2.03 \pm 0.18$ & $\mathrm{~N} 4$ & $7.53 \pm 0.75$ \\
V5 & $12.07 \pm 0.60$ & $\mathrm{~N} 5$ & $8.82 \pm 0.62$ \\
V6 & $7.72 \pm 0.31$ & $\mathrm{~N} 6$ & $0.04 \pm 0.00$ \\
V7 & $0.07 \pm 0.00$ & $\mathrm{~N} 7$ & $0.01 \pm 0.00$ \\
V8 & $14.27 \pm 0.43$ & $\mathrm{~N} 8$ & $1.38 \pm 0.10$ \\
V9 & $19.96 \pm 0.60$ & $\mathrm{~N} 9$ & $2.69 \pm 0.08$ \\
V10 & $8.72 \pm 0.70$ & $\mathrm{~N} 10$ & $2.86 \pm 0.14$ \\
V11 & $0.01 \pm 0.00$ & $\mathrm{~N} 11$ & $7.41 \pm 0.44$ \\
V12 & $8.33 \pm 0.83$ & $\mathrm{~N} 12$ & $17.11 \pm 1.20$ \\
V13 & $7.37 \pm 0.29$ & $\mathrm{~N} 13$ & $21.49 \pm 1.93$ \\
V14 & $8.71 \pm 0.44$ & $\mathrm{~N} 14$ & $8.76 \pm 0.44$ \\
V15 & $0.06 \pm 0.00$ & $\mathrm{~N} 15$ & $0.04 \pm 0.00$ \\
V16 & $0.01 \pm 0.00$ & $\mathrm{~N} 16$ & $0.01 \pm 0.00$ \\
\hline
\end{tabular}

pathogen, which is able to live in animal and plants. It is a spore-producing microorganism, causing pulmonary mycosis, and it is often found in bird excrements. Some researches were conducted in demonstrate the antifungal activity of tea extracts towards clinical strains of Cryptococcus neoformans [43, 44]: for this reason, it can be hypothesized that, being commonly found in soil samples, this yeast represents a risky microorganism, especially for immunocompromised individuals.

By comparing the results with the available survey from EHIA (European Herbal Infusions association) [45], it can be evidenced that aerobic plate count (total bacterial count) results in the majority of cases between the $10^{6}-10^{8} \mathrm{UFC} / \mathrm{g}$ range, compared to our samples, whose microbial loads does are not higher than $10^{5} \mathrm{UFC} / \mathrm{g}$; molds and yeasts counts result lower $\left(\leq 10^{3} \mathrm{UFC} / \mathrm{g}\right)$ than the available data from EHIA $\left(10^{3}-10^{6} \mathrm{UFC} / \mathrm{g}\right.$ range) [45]. An available research concerning tea microbiome supports the present study outcomes, reporting the majority of isolates belonging to Bacillus genus for Bacteria, and to Aspergillus and Cladosporium genera for molds [46].

\section{Mycotoxins}

Various species of molds are isolated from analyzed tea samples. Aspergillus niger, whose 16 isolates have been characterized in this study, has been associated with tea [47]. It was moreover reported that $7 \%$ of Aspergillus niger isolated from herbal teas produce
OTA [33]. In Europe there are not regulations for the OTA concentration in tea. Only coffee is regulated by Commission Regulation (EC) No 1881/2006 with a maximum allowed concentration of $5 \mu \mathrm{g} / \mathrm{Kg}$ in roasted coffee and ten in green coffee. With respect to these limits, our positive samples seems to be substantially contaminated. Other studies report high OTA concentration in tea. Haas et al. [34] report a $94.7 \mu \mathrm{g} / \mathrm{Kg}$ concentration of OTA in a Pu-erh tea sample, while Malir et al. [13] report a concentration of $250 \mu \mathrm{g} / \mathrm{Kg}$ in a black tea sample and a mean OTA concentration of $33.1 \mu \mathrm{g} / \mathrm{Kg}$ based on 12 samples of black tea. The OTA transfer in beverage after the infusion procedure have demonstrated a high influence from the infuse $\mathrm{pH}$ [14].

Based on Commission Regulation (EC) No 1881/ 2006 indications, available data show that seven black tea samples and ten green tea samples (overall, half the samples evaluated) present ochratoxin A concentrations higher than the $5 \mu \mathrm{g} / \mathrm{Kg}$ limit. Analysing green tea results, six samples reported OTA values between 7 and $9 \mu \mathrm{g} / \mathrm{Kg}$, four samples over $9 \mu \mathrm{g} / \mathrm{Kg}$, with V3 and V9 showing concentrations higher than $14 \mu \mathrm{g} / \mathrm{Kg}$ (three times the indicated limit). Black tea results registered, for three samples, OTA values between 7 and $9 \mu \mathrm{g} / \mathrm{Kg}$ and, for samples N3, N12 and $\mathrm{N} 13$, OTA concentrations higher than $17 \mu \mathrm{g} / \mathrm{Kg}$. The observed values were different in the green and black samples; this can be explained by differences in the final $\mathrm{pH}$. Since the infuse was prepared with pure water to minimize the cross contamination and to standardize the procedure, the high difference in the ochratoxin A transfer can suggest to investigate this phenomenon in real conditions using drinking water that can modify the tea soluble acids.

\section{Conclusion}

Hygiene monitoring performed on tea samples brought out that such food product does not contain microbial loads which can be harmful for consumers. On the other hand, the attention has to be focused on mycotoxins migration, especially ochratoxin A, whose concentrations resulted over the indicated limits for food products in the $50 \%$ analyzed samples. The proper storage of the product is however crucial during the production chain, but particularly for retailers and consumers: storage in humid environment constitutes the highest human health risk, for tea and tea products, triggering the growth of potentially pathogenic microorganisms, especially those able to produce toxins. The integration of standardized cultural methods with molecular characterization of microorganisms is able to consent the detection of highly pathogenic strains, employing faster and more precise protocols, aiming to the optimization of health risk assessment. 


\section{Abbreviations}

BF3: Borontrifluoride; C. sinensis: Camellia sinensis; DRBC: Rose-Bengal chloramphenicol agar; HPLC-FLD: High-performance liquid chromatography with fluorescence detection; ISO: International Organization for Standardization; ITS: Internal Transcribed Spacer; NaCl: Sodium Chloride; OTA: Ochratoxin A; PCA: Plate Count Agar; PCR: Ploymerase Chain Reaction; PEG: Polyethylene glycol; TBC: Total Bacterial Count; TBX: Tryptone Bile Agar with X-Glucuronide; TSC: Tryptose Sulphite Cycloserine agar

\section{Acknowledgements}

A special thanks to Dr. Maria Comparone for her technical help in laboratory.

\section{Funding}

This research did not receive any specific grant from funding agencies in the public, commercial, or not-for-profit sectors.

\section{Availability of data and materials}

The majority of the data is included in the manuscript. The raw data and other material used in the reported research shall be available only on request. Please contact Olga de Castro (odecastr@unina.it) or Federica Carraturo (federica.carraturo@unina.it) to request additional data.

\section{Author's contributions}

ODC conceived the idea, collected the tea black and green materials, carried out the DNA barcoding genetic analyses in tea and microbial samples, led the writing, supervising the manuscript. FC performed the microbiological analyses, interpreted of microbiological outcomes, led the writing and revision of the manuscript. JT contributed to chemical reagents, performed the mycotoxin characterization and drafted the mycotoxins part of the manuscript; MG conceived supported the design of the study, provided the microbiological analysis reagents and revised the manuscript. FA designed the study, supported data interpretation and revised the manuscript. ODC and ADL carried out the DNA barcoding genetic analyses in tea and microbial samples and supported the interpretation of barcoding results; MT contributed to chemical reagents, supported the analysis and the interpretation of mycotoxins data; AM and PC, contributed to microbiological analysis preparation, supported the writing of study microbiology methods and helped with the revision of the final version of the manuscript. All authors read and approved the final manuscript.

\section{Ethics approval and consent to participate}

Not Applicable.

\section{Consent for publication}

Not Applicable.

\section{Competing interests}

The authors declare that they have no competing interests.

\section{Publisher's Note}

Springer Nature remains neutral with regard to jurisdictional claims in published maps and institutional affiliations.

\footnotetext{
Author details

${ }^{1}$ Department of Biology, University of Naples Federico II, Via Cinthia, 80126 Naples, Italy. ${ }^{2}$ Department of Biology, University of Naples Federico II, Via Foria 223 - Orto Botanico, 80139 Naples, Italy. ${ }^{3}$ Department of Medicine and Surgery, University of Salerno, Via Giovanni Paolo II 132, 84084 Salerno, Italy. ${ }^{4}$ Department of Veterinary Medicine and Animal Production, University of Naples Federico II, Via Delpino 1, 80137 Naples, Italy. ${ }^{5}$ S.G. Moscati Hospital, Contrada Amoretta, 83100 Avellino, Italy. ${ }^{6}$ Faculty of Humanities, University of Suor Orsola Benincasa, Santa Caterina da Siena 37, 80135 Naples, Italy. ${ }^{7}$ Department of Chemical Sciences, University of Naples Federico II, 80126 Naples, Italy.
}

Received: 11 July 2017 Accepted: 18 December 2017

Published online: 05 January 2018

\section{References}

1. Zhao ZJ, Tong HR, Zhou L, Wang EX, Liu QJ. Fungal colonization of Pu-erh tea in Yunnan. J Food Safety. 2010;30:769-84.

2. Dugar K. Tea processing techniques and classification of tea. Tea Stories. Stil Steeping. The Teabox Blog. 2016. https://tea101.teabox.com/tea-processedclassified/. Accessed 16 Dec 2016.

3. Le GC. The Varieties of Formosa Oolong. The Art Of Tea Magazine 1. 2016. http//http://www.artoftea.com/. Accessed 10 Dec 2016.

4. Lund B, Baird-Parker AC, Gould GW. The microbiological safety and quality of food. Gaithersburg: Aspen Publishers, Inc; 2000. p. 960-4.

5. American Herbal Product Association (AHPA). Recommended microbial limits for botanical ingredients (in colony-forming units (CFU)/g). 2016. http://www.ahpa.org/Portals/0/PDFs/Policies/14_0206_AHPA_micro_limits_ comparisons.pdf. Accessed 16 Dec 2016.

6. Scientific Committee on Foods, European Union. Opinion on the potential microbiological risk arising from the presence of moisture in tea. 2016. http://www.thie-online.eu/tea/quality-assurance/. Accessed 16 Dec 2016.

7. Tea and Herbal Infusions Europe. THIE's Recommended Microbiological Specification for Herbal Infusions (Dry). Hamburg (Germany). 2016. http:// www.thie-online.eu/fileadmin/inhalte/Publications/HFI/4_2015-06-30_THIE_ Recommended_microbiological_specifications.pdf. Accessed 2 Dec 2016.

8. De Castro O, Comparone M, Di Maio A, Del Guacchio E, Menale B, Troisi J, Aliberti F, Trifuoggi M, Guida M. What is in your cup of tea? DNA verity test to characterize black and green commercial teas. PLoS One. 2017;12:e0178262.

9. McClane BA. The complex interactions between Clostridium perfringens enterotoxin and epithelial tight junctions. Toxicon. 2001;39:1781-91.

10. Paredes-Sabja D, Gonzalez M, Sarker MR, Torres JA. Combined effects of hydrostatic pressure, temperature, and $\mathrm{pH}$ on the inactivation of spores of Clostridium perfringens type a and Clostridium sporogenes in buffer solutions. J Food Sci. 2007;72:M202-6.

11. Sarker MR, Shivers RP, Sparks SG, Juneja VK, McClane BA. Comparative experiments to examine the effects of heating on vegetative cells and spores of Clostridium perfringens isolates carrying plasmid genes versus chromosomal enterotoxin genes. Appl Environ Microb. 2000;66:3234-40.

12. Zhang Y, Skaar I, Sulyok M, Liu X, Rao M, Taylor JW. The microbiome and metabolites in fermented Pu-erh tea as revealed by high-throughput sequencing and quantitative multiplex metabolite analysis. PLoS One. 2016;11:e0157847.

13. Iha MH, Trucksess MW. Aflatoxins and ochratoxin a in tea prepared from naturally contaminated powdered ginger. Food Addit Contam. 2010; 10(A27):1142-7.

14. Malir F, Ostry V, Pfohl-Leszkowicz A, Toman J, Bazin I, Rouba T. Transfer of Ochratoxin a into tea and coffee beverages. Toxins. 2014;6:3438-53.

15. ISO 4833-1:2013. Microbiology of the food chain - Horizontal method for the enumeration of microorganisms; Part 1: Colony count at $30^{\circ} \mathrm{C}$ by the pour plate technique. 2016. http://www.iso.org/iso/catalogue_detail. htm? csnumber=53728. Accessed 15 Dec 2016.

16. ISO 21527-1:2008. Microbiology of food and animal feeding stuffs - Horizontal method for the enumeration of yeasts and moulds - Part 1: Colony count technique in products with water activity greater than 0.95. 2016. https://www. iso.org/standard/38275.html. Accessed 15 Dec 2016.

17. ISO 16649-2:2001. Microbiology of food and animal feeding stuffs. Horizontal method for the enumeration of beta-glucuronidase-positive Escherichia coli; Part 2: Colony-count technique at 44 degrees C using 5bromo-4-chloro-3-indolyl beta-D-glucuronide. 2016. http://www.iso.org/iso/ catalogue_detail.htm?csnumber=29824. Accessed 15 Dec 2016.

18. ISO 13720:2010. Meat And Meat Products - Enumeration Of Presumptive Pseudomonas spp. 2016. https://www.iso.org/standard/45099.html. Accessed 15 Dec 2016.

19. ISO 7937:2004. Microbiology of food and animal feeding stuffs - Horizontal method for the enumeration of Clostridium perfringens - Colony-count technique. 2016. https://www.iso.org/standard/36588.html. Accessed 15 Dec 2016.

20. Marchesi JR, Sato T, Weightman AJ, Martin TA, Fry JC, Hiom SJ, Dymock D, Wade WG. Design and evaluation of useful bacterium-specific PCR primers that amplify genes coding for bacterial 165 rRNA. Appl Environ Microb. 1998;64:795-9.

21. White TJ, Bruns TD, Lee $S$ and Taylor J. Amplification and direct sequencing of fungal ribosomal RNA genes for phylogenetics, in PCR protocols: a guide to methods and applications, ed. by Innis MA, Gelfand DH, Sninsky JJ and White TJ, Academic Press, San Diego, 315-322 (1990). 
22. Di Maio A, De Castro O. SSR-patchwork: an optimized protocol to obtain a rapid and inexpensive SSR library using first generation sequencing technology. Appl Plant Sci. 2013;1:1200158.

23. Altschul SF, Madden TL, Schäffer AA, Zhang J, Zhang Z, Miller W, Lipman JD. Gapped BLAST and PSI-BLAST: a new generation of protein database search programs. Nucleic Acids Res. 1997;25:3389-402.

24. Ingham E, Moldenke AR, Edwards CA. Soil biology primer. Ames: NRCS Soil Quality Institute; 1999. p. 1-56.

25. Zhao M, Xiao W, Ma Y, Sun T, Yuan W, Tang N, Zhang D, Wang Y, Li Y, Zhou $\mathrm{H}$, Cui $X$. Structure and dynamics of the bacterial communities in fermentation of the traditional Chinese post-fermented pu-erh tea revealed by 165 rRNA gene clone library. World J Microb Biot. 2013;29:1877-84

26. Song T. Microbial composition of four kinds of tea with different degree of oxidation. Lund (Sweden): Department Food Technology and Nutrition, Lund University Libraries; 2016.

27. Hauser E, Kaempfer P, Busse HJ. Pseudomonas psychrotolerans sp. nov. Int J Syst Evol Micr. 2004;54:1633-7.

28. Ingham SC, Reyes JC, Schoeller NP, Lang MM. Potential use of presumptive Enterococci and staphylococci as indicators of sanitary condition in plants making hard Italian-type cheese. J Food Protect. 2000;63:1697-701.

29. Kato Tanaka Y, Horie N, Mochida K, Yoshida Y, Okugawa E, Nanjo F. Pantoea theicola sp. nov., isolated from black tea. Int J Syst Evol Micr. 2015;65:3313-9.

30. Popp A. Cleenwerck. I, Iversen C, de Vos P and Stephan R. Pantoea gaviniae sp. nov. and Pantoea calida sp. nov., isolated from infant formula and an infant formula production environment. Int J Syst Evol Micr. 2010;60:2786-92.

31. Centers for Disease Control and Prevention. Fatal Foodborne Clostridium perfringens illness at a state psychiatric hospital, Louisiana, 2010. MMWR. 2012;61:605-8.

32. Halt M. Moulds and mycotoxins in herb tea and medicinal plants. Eur J Epidemiol. 1998;14:269-74.

33. Storari M, Dennert FG, Bigler L, Gessler C, Broggini GAL. Isolation of mycotoxins producing black Aspergilli in herbal teas available on the Swiss market. Food Control. 2012;26:157-61.

34. Haas D, Pfeifer B, Reiterich C, Partenheimer R, Reck B, Buzina W. Identification and quantification of fungi and mycotoxins from Pu-erh tea. Int J Food Microbiol. 2013;166:316-22.

35. Samson RA, Houbraken J, Thrane U, Frisvad JC, Andersen B. Food and indoor fungi. Utrecht: CBS-KNAW Fungal Biodiversity Centre; 2010. p. 1-390.

36. Ndagijimanaa M, Chaves-López C, Corsettib A, Tofalob R, Sergi M, Paparella A, Guerzonia ME, Suzzi G. Growth and metabolites production by Penicillium brevicompactum in yoghurt. Int J Food Microbiol. 2008;127:276-83.

37. Domsch KH, Gams W, Anderson T. Compendium of soil fungi. London: Academic Press Ltd; 1980. p. 1-860.

38. Gryganskyi AP, Lee SC, Litvintseva AP, Smith ME, Bonito G, Porter TM, Anishchenko IM, Heitman J, Vilgalys R. Structure, function, and phylogeny of the mating locus in the Rhizopus oryzae complex. PLoS One. 2010;5:e15273.

39. Schubert K, Groenewald JZ, Braun U, Dijksterhuis J, Starink M, Hill CF, Zalar P, de Hoog G. S and Crous PW. Biodiversity in the Cladosporium herbarum Complex (Davidiellaceae, Capnodiales), with standardisation of methods for Cladosporium taxonomy and diagnostics. Stud Mycol. 2007:58:105-56.

40. Bensch K, Groenewald JZ, Braun U, Dijksterhuis J, de Jesús Y-MM, Crous PW. Common but different: the expanding realm of Cladosporium. Stud Mycol. 2015;82:23-74

41. Biswas SK, Yokoyama K, Nishimura K, Miyaji M. Molecular phylogenetics of the genus Rhodotorula and related basidiomycetous yeasts inferred from the mitochondrial cytochrome b gene. Int J Syst Evol Micr. 2001;51:1191-9.

42. Kim JY. Isolation of Sporidiobolus ruineniae CO-3 and characterization of its extracellular protease. J Korean Soc Appl Bi. 2009;52:1-10.

43. Cheruiyot SE, Muturi M, Bii C. Antifungal activities of Camellia sinensis crude extract on selected pathogenic and Mycotoxic fungi. J Bacteriol Mycol. 2015;2:id1015.

44. Koech KR, Wachira FN, Ngure RM, Orina IA, Wanyoko JK, Bii C, Karori SM. Antifungal activity of crude tea extracts. Afr J Agric Res. 2013;8:2086-9.

45. Kolb N. Microbiological status of untreated herbal materials. Eur Herb Infusions Assoc. 1999;95:263-9.

46. Elshafie AE, Al-Lawatia T, Al-Bahry S. Fungi associated with black tea and tea quality in the Sultanate of Oman. Mycopathologia. 1999;145:89-93.

47. Zhang Y, Skaar I, Sulyok M, Liu X, Rao M, Taylor JW. The microbiome and metabolites in fermented Pu-erh tea as revealed by high-throughput sequencing and quantitative multiplex metabolite analysis. PLoS One. 2016;11(6):e0157847.

\section{Submit your next manuscript to BioMed Central and we will help you at every step:}

- We accept pre-submission inquiries

- Our selector tool helps you to find the most relevant journal

- We provide round the clock customer support

- Convenient online submission

- Thorough peer review

- Inclusion in PubMed and all major indexing services

- Maximum visibility for your research

Submit your manuscript at www.biomedcentral.com/submit 